\title{
Brain Injury Induced by Intracerebral Injection of Interleukin-1beta and Tumor Necrosis Factor-alpha in the Neonatal Rat
}

\author{
ZHENGWEI CAI, SHUYING LIN, YI PANG, AND PHILIP G. RHODES \\ Department of Pediatrics, Division of Newborn Medicine, University of Mississippi Medical Center, \\ Jackson, Mississippi 39216, U.S.A.
}

\begin{abstract}
To examine the possible role of inflammatory cytokines in mediating neonatal brain injury, we investigated effects of intracerebral injection of IL-1beta (IL-1 $\beta$ ) or tumor necrosis factoralpha $(\mathrm{TNF} \alpha)$ on brain injury in the neonatal rat. A stereotaxic intracerebral injection of IL- $1 \beta$ or TNF $\alpha$ (10 ng per pup) was performed in postnatal day 5 (P5) SD rats. Although no necrosis of neurons was found, increased astrogliosis, as indicated by GFAP positive staining was observed 24 and $72 \mathrm{~h}$ following the injection of IL- $1 \beta$ or TNF $\alpha$. IL- $1 \beta$ induced apoptotic cell death in the rat brain $24 \mathrm{~h}$ after the injection, as indicated by increases in positive TUNEL staining and caspase- 3 activity, and apoptotic cell death was partially blocked by systemic administration of NBQX, an antagonist of the AMPA glutamate receptor. IL- $1 \beta$ also significantly reduced the number of developing oligodendrocytes (OLs) $24 \mathrm{~h}$ after the injection and this impairment was not prevented by NBQX. On the contrary, TNF $\alpha$ induced a much smaller increase in the number of TUNEL positive cells and did not reduce the number of developing OLs. By P8, myelin basic protein (MBP) was clearly detected in the control rat brain, while MBP positive staining was very weak, if any, in the IL- $1 \beta$ treated
\end{abstract}

\section{ABSTRACT}

rat brain. MBP expression in the TNF $\alpha$ treated rat brain was less affected. The overall results indicate that IL- $1 \beta$ may directly cause injuries to developing OLs and impair myelination in the neonatal rat brain and TNF $\alpha$ may have different roles in mediating brain injury. (Pediatr Res 56: 377-384, 2004)

$\quad$ Abbreviations
IL-1 $\boldsymbol{\beta}$, interleukin-1beta
TNF $\boldsymbol{\alpha}$, tumor necrosis factor-alpha
PVL, periventricular leukomalacia
LPS, lipopolysaccharide
HI, hypoxia-ischemia
OL, oligodendrocyte
NF, neurofilament
GFAP, glial fibrillary acidic protein
MBP, myelin basic protein
NBQX, 6-nitro-7-sulfamoylbenzoquinoxaline-2,3-dione
PN, polymorphonuclear
TUNEL, terminal deoxynucleotidyl transferase-mediated
uridine 5'-triphosphate-biotin nick end labeling

White matter disease, periventricular leukomalacia (PVL) in particular, is an important form of brain injury in very preterm infants, and is closely associated with severe neurologic disorders including cerebral palsy. Increasing evidence indicates that in addition to perinatal hypoxia-ischemia (HI), maternal or placental infection may also be a major contributor to PVL (1-4) and that inflammatory cytokines derived from maternal infection are mediators between maternal infection and PVL in the infant brain $(1,2,5)$.

Both clinical and experimental animal studies have provided supporting evidence for this hypothesis. Occurrence of PVL is frequently associated with increased concentrations of inflam-

Received November 3, 2003; accepted April 21, 2004.

Correspondence: Zhengwei Cai, Ph.D., Department of Pediatrics, Newborn Medicine, University of Mississippi Medical Center, 2500 North State Street, Jackson, MS 39216, U.S.A.; e-mail: zcai@ped.umsmed.edu

This work was supported by HD 35496 .

DOI: 10.1203/01.PDR.0000134249.92944.14 matory cytokines such as tumor necrosis factor- $\alpha$ (TNF $\alpha$ ), IL-1- $\beta$ (IL-1 $\beta$ ) and IL-6 in the infant brain (6-9), in the cord blood (10) or amniotic fluid (11). Maternal administration of endotoxin (lipopolysaccharide, LPS) induces PVL-like white matter injury in fetal sheep brain $(12,13)$ and results in apoptotic cell death and gliosis in the offspring rat brain $(14,15)$. White matter injuries in these studies are associated with the LPS-induced increase in expression of TNF $\alpha$, IL- $1 \beta$ or IL- 6 in the fetal or offspring brain $(12,14,15)$. The protective effects of IL-1 receptor antagonists (IL-1ra) and/or soluble TNF $\alpha$ receptor or TNF $\alpha$ antibodies in HI-induced brain injury (16-21) have provided further evidence that inflammatory cytokines have important roles in mediating neonatal brain injury. However, the detailed role of inflammatory cytokines in mediating neuronal and/or white matter injury is still not completely understood. Controversial consequences following application of exogenous IL- $1 \beta$ or TNF $\alpha$ have been reported. Intracerebral injection of IL-1 $\beta$ has been found nonneurotoxic (19) or to 
induce apoptotic cell death and vasogenic edema (22) in the adult rat brain. In vitro studies show that IL-1 $\beta$ promotes oligodendrocyte $(\mathrm{OL})$ death through glutamate excitotoxicity (23). TNF $\alpha$ induces damage to the blood-brain barrier in vivo (24) and causes death of OLs in vitro $(25,26)$. TNF $\alpha$ has also been reported to attenuate NMDA or AMPA-induced neurotoxicity $(27,28)$, to promote proliferation of OL progenitors and remyelination in vivo (29), and to protect neurons against amyloid- $\beta$-peptide toxicity in vitro (30).

In our previous work, we used an intracerebral injection of LPS to create a similar scenario as that during maternal infection. LPS is a component of the cell wall of Gram-negative bacteria and is responsible for most of the inflammatory effects of infection from Gram-negative bacteria. We found that intracerebral injection of LPS in the neonatal rat induced great increases in IL- $1 \beta$ and TNF $\alpha$ concentrations in the brain and resulted in selective white matter injury (31). Co-administration of LPS with IL-1ra, but not with antibodies to TNF $\alpha$, protected the rat brain from LPS-induced white matter injury (32). To further examine the role of inflammatory cytokines in mediating brain injury, we investigated effects of intracerebral injection of IL- $1 \beta$ or TNF $\alpha$ on brain injury in the neonatal rat.

\section{MATERIALS AND METHODS}

Chemicals. Unless otherwise stated, all chemicals used in this study were purchased from Sigma Chemical Co. (St. Louis, MO, U.S.A.). Recombinant rat IL- $1 \beta$ and rat TNF $\alpha$, as well as Caspase-3 activity assay kit, were purchased from R\&D System (Minneapolis, MN, U.S.A.). Monoclonal mouse antibodies against $\mathrm{O} 4, \mathrm{O} 1$ oligodendrocytes or myelin basic protein (MBP), and polyclonal rabbit antibodies against glial fibrillary acidic protein (GFAP) or NG2 were purchased from Chemicon (Temecula, CA, U.S.A.). Monoclonal mouse antibody against rat CD43 was purchased from Serotec (Raleigh, NC, U.S.A.). Apoptosis detection kit was purchased from Serologicals (Norcross, GA, U.S.A.).

Intracerebral injection and animal treatment. Ninety-six rat pups were used in this study. The number of the rat pups injected with IL-1 $\beta$ or TNF $\alpha$ was 30 each. Twenty-two rat pups were injected with sterile saline containing $0.1 \%$ BSA (BSA) as the control. Eight rat pups were injected with IL-1 $\beta$ followed by intraperitoneal administration of 6-nitro-7sulfamoylbenzoquinoxaline-2,3-dione (NBQX), an antagonist of the AMPA receptor. Six naïve rat brains were used for determination of the baseline level of caspase- 3 activity and immunostaining. Intracerebral injection of IL- $1 \beta$ or TNF $\alpha$ to 5 -d old Sprague-Dawley rat pups of both sexes was performed as previously described $(31,32)$. Late OL progenitor cells, which have been proposed to be the major target in cerebral white matter injury in human infants (33), are the predominant OL lineage stage in the rat cerebral hemispheres between $\mathrm{P} 2$ to P7 (33). For ease of the stereotaxic injection, we performed intracerebral injection in P5 rats. Under light anesthesia with isoflurane (1.5\%), IL-1 $\beta$ or TNF $\alpha$ (10 ng per rat pup) in sterile saline containing $0.1 \%$ BSA (total volume of $2 \mu \mathrm{L}$ ) was administered to the rat brain at the location of $1.0 \mathrm{~mm}$ posterior and $1.0 \mathrm{~mm}$ lateral to the bregma, and $2.0 \mathrm{~mm}$ deep to the skull surface at the left hemisphere in a stereotaxic apparatus with a neonatal rat adapter. The dose of IL- $1 \beta$ and TNF $\alpha$ was chosen based on the peak concentrations of IL- $1 \beta$ and TNF $\alpha$ achieved in the rat pup brain following LPS administration as reported previously $(31,32)$ and on the published data $(19,22)$. The injection was completed in $5 \mathrm{~min}$ and the needle was kept in this position for an additional $2 \mathrm{~min}$ and then retrieved slowly out of the brain. The wound was sutured and the pups were placed on a thermal blanket $\left(34^{\circ} \mathrm{C}-35^{\circ} \mathrm{C}\right)$ for recovery before being returned to their dams. The accuracy of the injection site has been confirmed by the method of methyl green injection in some rat pups, as previously described (32). The injection site was located at the corpus callosum above the left ventricle. All animals survived the intracerebral injection. One and three days after the injection, rat pups were killed by transcardiac perfusion with normal saline followed by $4 \%$ paraformaldehyde for brain section preparation or by decapitation for brain tissue collection used in Caspase-3 activity assay. Consecutive frozen brain sections (near the injection site) in the thickness of $10 \mu \mathrm{m}$ were prepared in a cryostat for immunohistochemistry and brain injury examination. To examine effects of inflammatory cytokines on developing OLs, free-floating brain sections $(40 \mu \mathrm{m})$ were prepared in a freezing sliding microtome in the latter part of this study. For investigating mechanisms involved in the brain injury induced by IL- $1 \beta$, intraperitoneal injection of NBQX $(20 \mathrm{mg} / \mathrm{kg})$ was performed immediately after IL- $1 \beta$ injection and every $12 \mathrm{~h}$ thereafter until sacrifice, as described by Follett et al. (34). The experimental procedure was approved by the Institutional Animal Care and Use Committee at the University of Mississippi Medical Center and, in addition, was in accordance with the guidelines of the National Institutes of Health on the care and use of laboratory animals.

Immunohistochemical studies. Brain injury was estimated based on the results of hematoxylin and eosin (H\&E) staining and immunohistochemistry in consecutive frozen sections prepared from the rat brain 1 and $3 \mathrm{~d}$ (P6 and P8) after the intracerebral injection. For all brain injury studies, brain sections near the site of injection were used. Three sections from each brain were examined. For immunohistochemistry, the final concentrations of the primary antibodies were diluted as follows: CD43 for polymorphonuclear (PN) cells (1:200), GFAP for astrogliosis (1:300), MBP (1:100), neurofilament (NF, 1:100), and $\mathrm{O} 4\left(10 \mu \mathrm{g} / \mathrm{mL}\right.$, over night at $\left.4^{\circ} \mathrm{C}\right)$. For free-floating section immunostaining, the primary antibodies against NG2, O4 or O1 were used at a dilution of $1 \mu \mathrm{g} / \mathrm{mL}$. After being incubated with biotinylated second antibodies for $1 \mathrm{~h}$ at RT, brain sections were further incubated with FITC- or Cy3-conjugated avidin or the avidin-horseradish peroxidase system (ABC kit from Vector Laboratories, Burlingame, CA, U.S.A.) for an additional $1 \mathrm{~h}$ in dark at RT. In free-floating section immunostaining, DAPI $(100 \mathrm{ng} / \mathrm{mL})$ was simultaneously used to identify nuclei in the final visualization. Sections incubated in the absence of primary antibody were used as negative controls. Microglia were detected using lectin histochemistry. Biotinylated tomato lectin was used at a concentration of $10 \mu \mathrm{g} / \mathrm{mL}$ and the results were visualized using the Vector ABC system. 
To compare the inflammatory responses and brain injury markers among the treatment groups, positively stained cells were counted. For cell counting, a digital microscopic image for each brain section was captured at the area where the positive cells were most abundant. Cell number in each image was counted and the average of the three sections from each brain was taken. When the cellular boundary was not clearly separated (such as some $\mathrm{O} 4$ or $\mathrm{O} 1$ positive cells), numbers of DAPI-stained nuclei from the superimposed images were counted as the cell number. The size of the image measured by the National Institutes of Health software was $0.3 \mathrm{~mm}^{2}$. The results were expressed as the average number of cells per image.

TUNEL staining and double labeling. Apoptosis was detected using terminal deoxynucleotidyl transferase-mediated uridine 5'-triphosphate-biotin nick end labeling (TUNEL) kits and double labeling techniques were used to identify the cell type of the TUNEL positive cells. For TUNEL staining, the manufacturer's instructions were followed. Following incubation with terminal deoxynucleotidyl transferase for $1 \mathrm{~h}$ at $37^{\circ} \mathrm{C}$, the sections were incubated with the primary antibody for specific cell markers or with biotinylated lectin for $2 \mathrm{~h}$ at RT (GFAP, CD43, NF) or overnight at $4^{\circ} \mathrm{C}(\mathrm{O} 4)$. After washing, the sections were incubated with biotinylated donkey antirabbit or anti-mouse antibody (depending on the primary antibody) at a dilution of 1: 200 for $1 \mathrm{~h}$ at RT. When TUNEL staining was performed in combination with biotinylated lectin, the step of incubation with a secondary antibody was omitted. The sections were then incubated with a mixture of the fluorescein-labeled anti-digoxigenin conjugate and Cy3labeled avidin (1:200) for $0.5 \mathrm{~h}$ at RT in dark. After washing and mounting, the results were examined under a fluorescence microscope using appropriate excitation and emission filters. The TUNEL positive cells show green color and the Cy3 stained cells show bright orange color.

Caspase-3 activity. Elevation in caspase-3 activity is an early marker of apoptosis. Caspase- 3 activity in the rat brain was determined $24 \mathrm{~h}$ after injection with IL- $1 \beta$ or TNF $\alpha$ by an assay kit, following manufacturer's instruction. Briefly, the ipsilateral forebrain was weighed and homogenized in $4 \times$ volume of lysis buffer (wt/vol), and the homogenate was kept on ice for $10 \mathrm{~min}$. After centrifugation at $12,000 \times \mathrm{g}$ for 10 min at $4^{\circ} \mathrm{C}$, caspase- 3 activity in the supernatant was determined colorimetrically with a microplate reader (Bio-Tek, Winooski, VT, U.S.A.) at $405 \mathrm{~nm}$. Caspase-3 activity in the naïve rat pup brain was determined as the baseline level. Caspase-3 activity in the rat brain from other groups was expressed as a percentage of the baseline level.

Statistics. Data of cell counting and caspase-3 activity were presented as the means \pm SEM. The cell counting and caspase- 3 data were analyzed by one-way ANOVA followed by Student-Newman-Keuls test. Results with a $p<0.05$ were considered statistically significant.

\section{RESULTS}

Inflammatory responses and bleeding in the brain. Intracerebral injection of IL-1 $\beta$ or TNF $\alpha$ induced inflammatory responses in the rat brain, as indicated by increases in the number of CD43 positive PN cells and activated microglia. CD43 positive PN cells were rarely seen in the naïve and the saline-injected P6 or P8 (24 h or $3 \mathrm{~d}$ after the intracerebral injection) rat brain. Widely distributed $\mathrm{CD} 43$ positive $\mathrm{PN}$ cells (Fig. $1 A$ insert) were observed in the frontal cortex, the corpus callosum and the subventricular area in both hemispheres $24 \mathrm{~h}$ after IL- $1 \beta$ or TNF $\alpha$ administration. The number of CD43 positive PN cells in the IL- $1 \beta$-injected rat brain was similar to that in the TNF $\alpha$-injected rat brain ( $44.5 \pm 4.1$ versus $37.8 \pm$ 8.1 in the subventricular area, for example). By P8, the number of CD43 positive cells was reduced in both groups. As shown in Fig. $1 A$ and $B$, however, the IL- $1 \beta$-injected rat brain had more CD43 positive cells in the subventricular area compared with the TNF $\alpha$-injected rat brain $(21.8 \pm 1.1$ versus $2.8 \pm 1.1$ for left brain and $16.8 \pm 3.6$ versus $2.6 \pm 1.0$ for right brain, $p<0.01)$.

Microglia were widely distributed in the whole brain of the control and the naïve rats, and almost all the microglia were in the resting status (Fig. 1C). Injection of IL- $\beta$ greatly stimulated activation of microglia $24 \mathrm{~h}$ after the injection, especially at the frontal cortex and the subventricular area (Fig. 1D). Compared with IL-1 $\beta$, TNF $\alpha$ stimulated less microglia activation (Fig. $1 E$ ). The number of activated microglia stimulated by IL- $1 \beta$ and by TNF $\alpha$ in the subventricular area was $38.2 \pm 3.3$ versus $15.2 \pm 2.0$, respectively $(p<0.01)$. Although activated microglia stimulated by IL- $1 \beta$ in the frontal cortex area were also more than that stimulated by $\mathrm{TNF} \alpha$, the difference was not
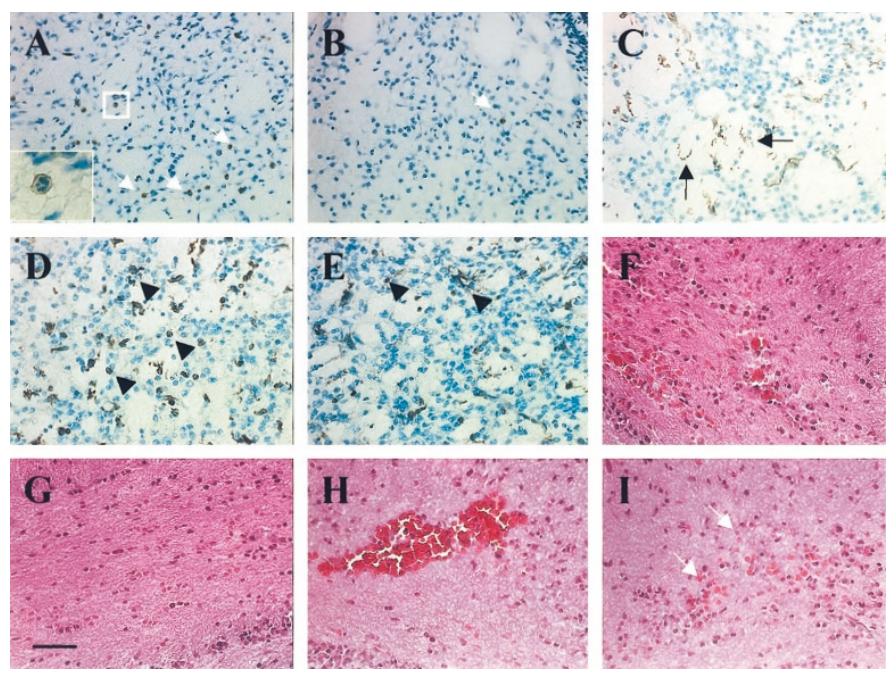

Figure 1. Inflammatory responses and hemorrhage in the neonatal rat brain following the intracerebral injection of IL- $1 \beta$ or TNF $\alpha$. Intracerebral injection was performed in 18 P5 rat brains (saline, 4; IL-1 $\beta, 7$ and TNF $\alpha, 7$ ). CD43 positive polymorphonuclear $(\mathrm{PN})$ cells, as indicated by white arrows, were greatly induced following injection of IL-1 $\beta(A)$, and, to a less extent, of TNF $\alpha$ $(B)$. The insert in $A$ is the magnified part of the white box. Microglia at resting status ( $C$, arrows indicated) were seen in the control rat brain. Activated microglia (arrowheads indicated) were found in IL-1 $\beta(D)$ and TNF $\alpha(E)$ treated rat brain. In $H \& E$ stained brain sections, hemorrhage was seen at the injection site in the control $(F)$, and IL- $1 \beta$ or $\operatorname{TNF} \alpha(H)$ treated rat brains. Hemorrhage was also seen at the contralateral side of rat brain treated with IL- $1 \beta$ or TNF $\alpha$ ( $I$, indicated by arrows), but not of the control rat brain $(G)$. Magnification: $100 \times$. Scale bar in G, $100 \mu \mathrm{m}$. 
of statistical significance $(34.4 \pm 3.1$ versus $24.6 \pm 4.1)$. By $\mathrm{P} 8$, activated microglia were rarely observed in the rat brain regardless of treatments.

H\&E staining showed that intracerebral injection with saline caused slight bleeding at the site of injection, as indicated by accumulation of red blood cells (Fig. 1F), but not at the contralateral side (Fig. $1 G$ ). Injection with IL- $1 \beta$ or TNF $\alpha$ not only caused more severe hemorrhage at the site of injection (Fig. $1 H$ ), but also caused bleeding at the contralateral corpus callosum and the frontal cortex $24 \mathrm{~h}$ after the injection (Fig. 1I). No other apparent histopathological changes were observed. By P8, accumulated red blood cells were not observed in either side of the brain in all treatment groups.

Astrogliosis. GFAP positive staining was observable at the corpus callosum area and the subcortical white matter tract in the control and the naïve P6 rat brain, but was never seen in the cortex (Fig. 2A), except at the needle path of some saline injected rat brains. IL-1 $\beta$ greatly increased GFAP positive cells at the frontal and the parietal cortex of the P6 rat brain (Fig. $2 B$ ), suggesting active astrogliosis. Similarly increased GFAP positive staining at the frontal and the parietal cortex in the $\mathrm{TNF} \alpha$-injected rat brain was also observed $24 \mathrm{~h}$ after the injection (Fig. 2C). The increased GFAP positive staining was also observed in the P8 IL-1 $\beta$ or TNF $\alpha$-injected rat brain (data not shown).

IL-1 $\beta$ increased TUNEL staining and Caspase-3 activity. TUNEL positive staining was rarely seen in the control rat brain (Fig. $3 A$ ). Injection of IL-1 $\beta$ significantly increased the number of TUNEL positive cells in the rat brain $24 \mathrm{~h}$ after the injection (Figs. $3 B$ and $4 A$ ). TUNEL positive cells were primarily localized in the outer layers of the cortex and in the subventricular area of both hemispheres. Double labeling indicated that the TUNEL positive cells were microglia (Fig. $3 D$, mostly distributed in the outer layers of the cortex), $\mathrm{O} 4$ positive OLs (Fig. $3 E$, in the corpus callosum and the subventricular area) and a few neurons (Fig. $3 F$ ). Neither the astrocyte nor the PN cell was found to be TUNEL positive (data not shown). Although the number of TUNEL positive cells was also increased following TNF $\alpha$ injection, the increase was significantly less than that induced by IL- $1 \beta$ (Figs. $3 C$ and $4 A$ ). The number of TUNEL positive cells in the subventricular area of the IL-1 $\beta$-injected and the TNF $\alpha$-injected rat brain was $14.4 \pm$ 1.2 and $4.4 \pm 1.1$, respectively, whereas that number in the control rat brain was $1.6 \pm 0.2$. No TUNEL positive cells were observed in the P8 rat brain regardless of treatments.

Consistent with the TUNEL staining data, caspase- 3 activity in the rat brain injected with IL- $1 \beta$ was significantly higher than that in the saline-injected or TNF $\alpha$-injected rat brain $24 \mathrm{~h}$ after the injection, suggesting that apoptotic cell death may occur following IL- $1 \beta$ administration (Fig. 5). The elevation of caspase-3 activity over that in the naïve rat brain was $107.7 \pm$ $9.3 \%, 147.9 \pm 2.0 \%$, and $114.6 \pm 4.9 \%$ for the control, the IL- $1 \beta$-injected and the TNF $\alpha$-injected groups, respectively.

$I L-1 \beta$ reduced MBP staining. MBP positive staining was clearly detected in the P8 control rat brain, primarily at the subcortical white matter tract, the internal capsule and the corpus callosum areas (Fig. 3G). A grade system was used to score the intensity of MBP positive staining. The score was
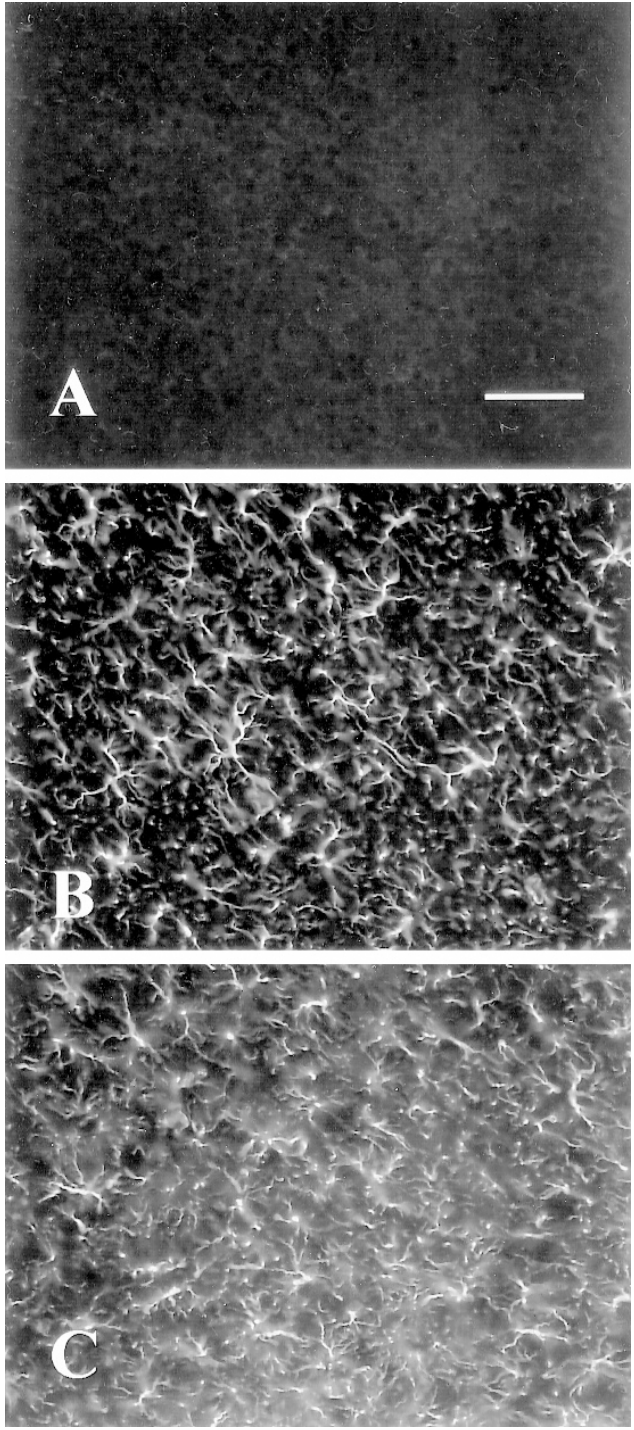

Figure 2. Representative GFAP immunostaining in the rat brain $24 \mathrm{~h}$ after intracerebral injection of IL- $1 \beta$ or TNF $\alpha$. The number of brains examined was the same as that in Fig. 1. Greatly increased GFAP positive cells at the frontal and the parietal cortex were observed in the IL-1 $\beta(B)$ or TNF $\alpha(C)$ treated rat brain, but not in the control rat brain $(A)$. Magnification: $100 \times$. Scale bar in $A$, $100 \mu \mathrm{m}$.

defined as the following: mild, 1 ; moderate, 2; strong, 3 ; and no immunoreactivity, 0. Digital microscopic images were taken at the above-mentioned three areas for each brain section. The average of the three scores was used to represent the grade of MBP staining for each brain. The MBP staining grade in the control, the IL- $1 \beta$-injected and the TNF $\alpha$-injected rat brain was $2.1 \pm 0.2,0.3 \pm 0.2$, and $1.8 \pm 0.3$, respectively. Intracerebral injection of IL- $1 \beta$ significantly suppressed expression of MBP and almost no positive or very weak positive MBP staining, if any, was detected in the P8 IL- $1 \beta$-injected rat brain (Fig. $3 H$ ). Expression of MBP in the rat brain injected with TNF $\alpha$ was less affected (Fig. 3I) and MBP staining score in the $\mathrm{TNF} \alpha$-injected rat brain was not significantly different from that in the control rat brain.

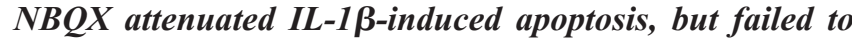
reduce IL-1ß-induced injury to developing OLs. MBP is 

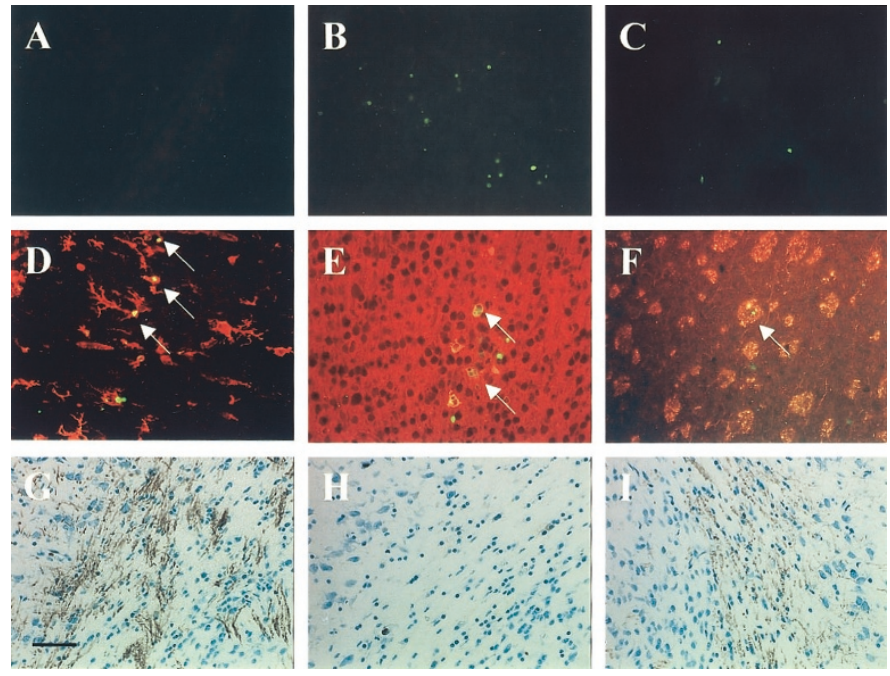

Figure 3. TUNEL staining in the 6-d old rat brain and MBP immunostaining in the 8-d old rat brain. Intracerebral injection was performed in 36 P5 rat brains (control, 8 ; IL-1 $\beta, 14$; and TNF $\alpha, 14$ ). Increased number of TUNEL positive cells (green) was observed in the subventricular area of the rat brain treated with IL-1 $\beta(B) 24 \mathrm{~h}$ after the injection. To a less extent, TNF $\alpha$ also induced TUNEL positive cells $(C)$, but no TUNEL positive cells were seen in the same area of the control rat brain $(A)$. Double labeling showed that TUNEL positive cells were lectin positive microglia ( $D$, arrows indicated), $\mathrm{O} 4+$ oligodendrocytes ( $E$, arrows indicated), and a few neurofilament positive neurons $(F)$. MBP positive staining (brown color) was observed at the corpus callosum area, the subcortical white matter and the internal capsule area in the P8 control rat brain injected with sterile saline $(G)$. Injection with IL-1 $\beta$ almost completely suppressed MBP expression $(H)$. Expression of MBP in the rat brain treated with TNF $\alpha$ was less affected $(I)$. Magnification: $100 \times$. Scale bar in $\mathrm{G}, 100 \mu \mathrm{m}$.

produced by OLs. It is possible that the suppressed expression of MBP following IL- $1 \beta$ injection is an indication of injury to $\mathrm{OL}$ development. The sequence of OL development is thought to begin with NG2+/O4- early OL progenitor cells, and to progress to $\mathrm{O} 4+/ \mathrm{O} 1$ - late $\mathrm{OL}$ progenitor cells, $\mathrm{O} 4+/ \mathrm{O} 1+$ immature OLs, and mature OLs that express MBP (33). We used antibodies against $\mathrm{NG} 2, \mathrm{O} 4$ or $\mathrm{O} 1$ to examine effects of IL- $1 \beta$ on OL development. Furthermore, in vitro experiments have shown that IL-1 $\beta$ promotes OL death through glutamate excitotoxicity and NBQX, an antagonist of the AMPA glutamate receptor, blocks OL apoptotic cell death induced by IL-1 $\beta$ in mixed glial cultures (23). To examine whether the effect of IL- $1 \beta$ on developing OLs is also mediated by the glutamate receptor, NBQX was administered following IL-1 $\beta$ injection. As shown in Fig. 4A, NBQX partially, but significantly, reduced the number of TUNEL positive cells induced by IL-1 $\beta$. It is an indication that the apoptotic cell death following IL-1 $\beta$ administration in the present study is at least partially associated with glutamate excitotoxicity. However, NBQX did not prevent the IL-1 $\beta$-induced injury to developing OLs (Figs. $4 B, C$ and 6 ). Neither IL- $1 \beta$ nor TNF $\alpha$ significantly altered density of NG2 positive cells, which were widely distributed in the whole brain section (Figs. $4 B, C$ ). O4 positive cells were largely distributed in the corpus callosum and subcortical white matter tract, and a few of them were distributed in the subventricular area. The $\mathrm{O} 1$ positive cells had a similar distribution as the $\mathrm{O} 4+$ cells did, except that the
A

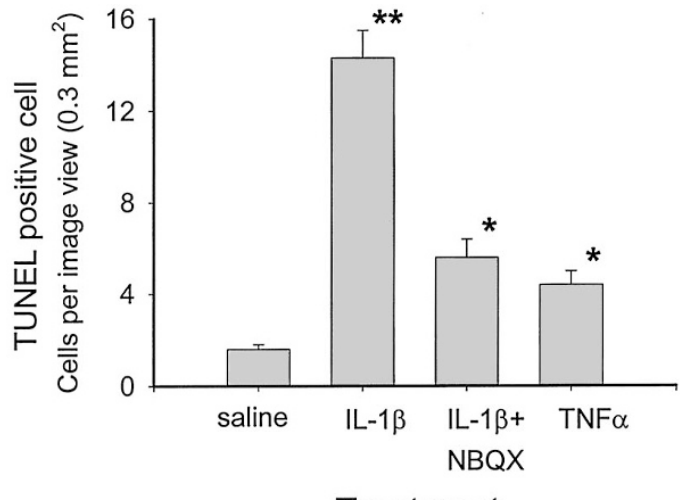

Treatment
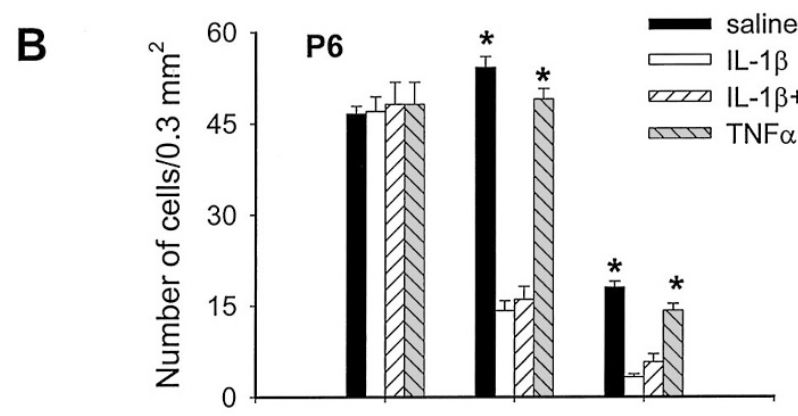

C

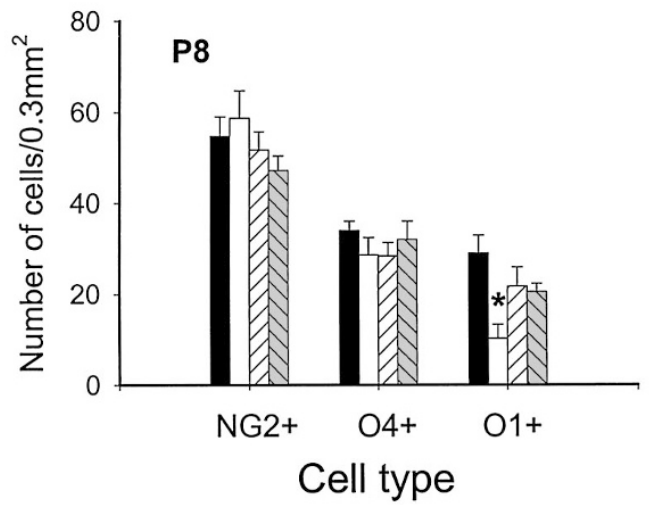

Figure 4. The number of TUNEL positive cells in the $\mathrm{P} 6$ rat brain $(A)$ and the number of $\mathrm{NG} 2+, \mathrm{O} 4+$ and $\mathrm{O} 1+$ cells per $0.3 \mathrm{~mm}^{2}$ in the P6 $(B)$ and P8 $(C)$ rat brain. TUNEL staining, immunostaining of developing OLs, and quantification of positively stained cells were performed in free-floating brain sections prepared as described in methods. Intracerebral injection was performed in 32 P5 rat brains ( 8 for each treatment group). ( $A$ ) IL- $1 \beta$ significantly increased TUNEL positive cells and this increase could be partially blocked by systemic injection of NBQX. To a less extent, TNF $\alpha$ also caused an increase in TUNEL positive cells. ${ }^{* *} p<0.05$ from the value for all groups ( $n=4$ for each group). $* p<0.05$ from the value for the control group. $(B)$ Intracerebral injection of IL- $1 \beta$ or TNF $\alpha$ did not significantly alter NG2 + cell number. IL- $1 \beta$, but not $\mathrm{TNF} \alpha$, significantly reduced $\mathrm{O} 4+$ and $\mathrm{O} 1+\mathrm{OLs} 24 \mathrm{~h}$ after the injection. NBQX was unable to prevent the reduction in $\mathrm{O} 4+$ and $\mathrm{O} 1+$ cell numbers. $* p$ $<0.05$ from the value for the IL- $1 \beta$ or the IL- $1 \beta+\mathrm{NBQX}$ groups $(n=4$ for each group). (C) By P8, numbers of $\mathrm{NG} 2+$ and $\mathrm{O} 4+$ cells were not different among groups. Number of $\mathrm{O} 1+$ cells in the rat brain treated with IL- $1 \beta$ was significantly lower than that in the control rat brain. ${ }^{*} p<0.05$ from the value for the control group ( $n=4$ for each group).

distribution of $\mathrm{O} 1+$ cells in the subventricular area was denser. IL- $1 \beta$, but not $\mathrm{TNF} \alpha$, significantly reduced the density of $\mathrm{O} 4+$ or $\mathrm{O} 1+$ cells $24 \mathrm{~h}$ after the injection (Figs. $4 B$ and 6 ). NBQX was unable to prevent the reduction of $\mathrm{O} 4+$ or $\mathrm{O} 1+$ cells 


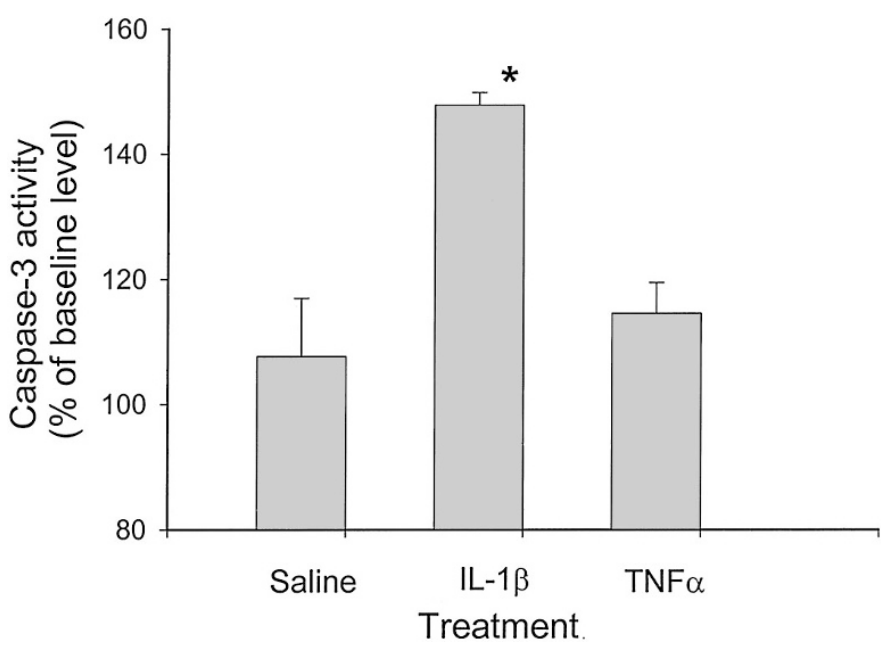

Figure 5. Caspase- 3 activity in the rat brain $24 \mathrm{~h}$ after the intracerebral injection of IL- $1 \beta$ or TNF $\alpha$. The control rats were injected with sterile saline containing $0.1 \%$ BSA. Caspase- 3 activity in the ipsilateral forebrain was determined as described in methods. The baseline level of caspase- 3 activity was determined in 3 naïve rat brains. Data are presented as the Mean \pm SEM of samples for each treatment $(n=4) .{ }^{*} p<0.05$ from the value for the other groups.
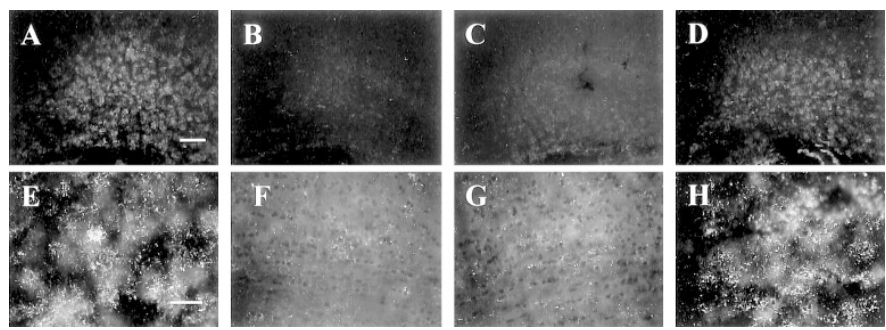

Figure 6. Representative immunostaining of $\mathrm{O} 4+$ cells $24 \mathrm{~h}$ after the intracerebral injection. The injection was performed in 16 P5 rat brains as described in methods (4 for each treatment group) and immunostaining was performed in free-floating brain sections. Strong O4+ staining was observed in the corpus callosum and subcortical white matter tract of the control rat brain $(A$ and $E$ ) and the rat brain injected with TNF $\alpha(D$ and $H)$. IL-1 $\beta$ injection greatly suppressed $\mathrm{O} 4+$ staining $(B$ and $F)$ and systemic treatment with NBQX was unable to prevent the loss of $\mathrm{O} 4+$ staining $(C$ and $G)$. Magnification: $A-D$, $25 \times ; E-H, 100 \times$. Scale bar in $A, 300 \mu \mathrm{m}$; Scale bar in $E, 100 \mu \mathrm{m}$.

caused by IL- $1 \beta$. By P8, the density of $\mathrm{O} 1+$ cells at the corpus callosum area in the IL- $1 \beta$ treated rat brain was still significantly lower than that in the control group, although the density of O4+ OLs was not significantly different among groups.

\section{DISCUSSION}

IL-1 $\beta$, when administered alone, has been reported to be nontoxic in many in vivo studies $(19,27,35)$ and only few studies have shown that IL-1 $\beta$ alone may induce apoptosis in the adult rat brain (22). Results from the current study provide supporting evidence that IL-1 $\beta$ may also induce apoptotic cell death in the neonatal rat brain. Furthermore, data from the current study show for the first time that IL-1 $\beta$ directly causes injury to developing OLs in the neonatal rat brain. Recent studies have shown that late OL progenitor cells (O4+/O1-) are selectively vulnerable to hypoxic-ischemic injury and coincide with the developmental window for vulnerability for human perinatal white matter injury $(33,36)$. Consistently, our results indicate that IL-1 $\beta$ selectively causes injury to $\mathrm{O} 4+$ OLs and to a less extent, to O1+ OLs (Figs. $4 B, C$ and 6). Our data support the hypothesis that the increased IL- $1 \beta$ concentrations $(6,7,11)$ derived from maternal infection may contribute to the occurrence of PVL in the infant brain.

Infiltrated leukocytes and activated microglia have been proposed to contribute to white matter damage induced by hypoxia-ischemia or inflammation/infection in extremely low gestational age newborns $(37,38)$. This hypothesis is supported by our observation that more severe brain injury in the IL- $1 \beta$ injected rat brain compared with that in the TNF $\alpha$-injected rat brain was associated with the higher increase in the number of activated microglia and $\mathrm{CD} 43+\mathrm{PN}$ cells in the neonatal rat brain following intracerebral injection of IL-1 $\beta$. Our data further indicate that the more severe brain injury in the IL- $1 \beta$ injected rat brain was linked with the more sustained elevation of the number of CD43+ PN cells in the IL- $1 \beta$-injected rat brain. This is an indication that sustained activation of leukocytes may lead to more damage than a short-lived inflammatory cytokine cascade (37). The increased number of CD43+ PN cells suggests that IL-1 $\beta$ and TNF $\alpha$ may cause injuries to the endothelia of blood vessels and the blood-brain barrier, and facilitate the process of transendothelial migration of the activated leukocytes from the circulation to the brain. Results from the current study did not reveal the detailed role of the increased PN cells and activated microglia in the injury to OLs. Although investigation of the role of activated leukocytes and microglia in white matter damage is beyond the scope of the current study, this is certainly a very important area in future investigations for the mechanisms involved in PVL-like white matter damage.

IL-1 $\beta$ induces apoptotic OL cell death in a mixed glial culture, but not in pure OL cultures, and its effect could be blocked by NBQX or CNQX, antagonists of the AMPA glutamate receptor (23). It is thought that IL-1 $\beta$ is not directly cytotoxic to OLs and that its effect on OLs is through the impairment of the glutamate transporter expression or glutamate-uptaking capacity of astrocytes $(23,39,40)$. In the current study, NBQX also attenuated apoptotic cell (including OL, Fig. $3 E$ ) death (Fig. $4 A$ ), suggesting that glutamate excitotoxicity is involved in the mechanism underlying apoptotic cell death induced by IL- $1 \beta$. However, results from the current study are not sufficient to support the possibility that apoptotic cell death observed in the present study is due to the blockade of glutamate uptake by astrocytes following IL- $1 \beta$ administration. Although astrogliosis stimulated by IL-1 $\beta$ (Fig. 2) might be an indication of injuries to astrocytes, similar astrogliosis was also observed following injection of TNF $\alpha$, which induced much less apoptotic cell death (Fig. 4A). Therefore, astrogliosis observed in the present study is rather an indication of the general response to the injury or an indication of trophic effects of IL- $1 \beta$ or TNF $\alpha$ on astrocytes (41).

HI-induced OL injury has been shown to be attenuated by AMPA receptor antagonist NBQX (34), whereas injuries to developing OLs induced by IL-1 $\beta$ in the present study were not affected by NBQX (Figs. 4 and 6), suggesting that the mechanism involved in the IL- $1 \beta$-induced injury to developing OLs may be different from that underlying OL injury caused by 
perinatal HI. Double labeling has shown that IL-1 $\beta$-induced apoptotic cell death includes developing OLs, and therefore, apoptosis may partially explain the reduction in $\mathrm{O} 4+$ and $\mathrm{O} 1+$ immunoreactivity one day after IL-1 $\beta$ injection. However, apoptotic cell death was observed primarily in the subventricular area, while loss of $\mathrm{O} 4+$ and $\mathrm{O} 1+$ immunoreactivity was largely seen in the corpus callosum and the subcortical white matter tract in the current study. Furthermore, the number of TUNEL positive cells was not comparable to the reduction in number of $\mathrm{O} 4+$ and $\mathrm{O} 1+$ OLs (Figs. 4A,B). In addition, NBQX reduced number of TUNEL positive cells, while it failed to prevent the loss of immunoreactivity of developing OLs. In the present study, it is unlikely that apoptosis is the major cause for the loss of $\mathrm{O} 4+$ and $\mathrm{O} 1+\mathrm{OL}$ immunoreactivity following IL-1 $\beta$ administration. Significant loss of O4+ and $\mathrm{O} 1+\mathrm{OL}$ immunoreactivity was observed one day after IL- $1 \beta$ injection in the current study. By P8, O4+ cell density in the IL- $1 \beta$-treated rat brain was not significantly different from that in the control rat brain (Fig. 4C). Because the loss of $\mathrm{O} 4+$ cells was observed following a single injection of IL- $1 \beta$, it is reasonable to speculate that prolonged exposure of OLs to IL-1 $\beta$ might result in more losses of OLs. Alternatively, this could be a reflection of either functional recovery of the injured OLs or a compensatory proliferation or maturation of $\mathrm{NG} 2+$ OLs to O4+ OLs. The significantly reduced O1+ OLs in the P8 IL-1 $\beta$-treated rat brain could result from the lower number of O4+ OLs for differentiation in the P6 rat brain. Functional recovery of injured OL proliferation and maturation of OL progenitors as indicated by restoration of the lost MBP staining in the neonatal rat brain has been reported after moderate, but not after more severe, cerebral hypoxia-ischemia (42). Since no necrotic or dead cells were found in the H\&E stained sections from either the P6 or the P8 rat brain, it is likely that IL- $1 \beta$ did not kill OLs, but instead impaired OL function or delayed OL development and differentiation. The present data have not provided direct evidence for this possibility and further investigation is needed.

$\mathrm{TNF} \alpha$ has been reported to induce damage of the bloodbrain barrier in vivo (41) and cause death of OLs in vitro $(25,26)$. In the present study, TNF $\alpha$ did not cause major injury to OLs compared with IL-1 $\beta$ and induced far less severe apoptosis compared with that in the IL- $1 \beta$-treated rat brain, although it stimulated similar astrogliosis (Fig. 2) and hemorrhage as that by IL-1 $\beta$ (Fig. 1). The lack of effects of TNF $\alpha$ on OL injury observed in this study suggests that TNF $\alpha$ and IL-1 $\beta$ may play different roles in mediating brain white matter injury. Enhanced TNF $\alpha$ expression induced by LPS has been found not to trigger apoptosis in glial cells, both in vivo and in vitro (43). Failure of TNF $\alpha$, at doses either lower or higher than that used in the present study, in stimulation of apoptotic cell death has also been reported in adult rat brains by other investigators (22). These authors find that intracerebral injection of IL-1 $\beta$ stimulates expression of the proapoptotic factor Bax and the antiapoptotic factor $B c l-2$ and that IL- $1 \beta$ stimulated apoptosis is associated with the presence of more Bax expressing cells than $B c l-2$ expressing cells (22). They also find IL- $1 \beta$-induced apoptotic cell death is closely associated with the extent of inflammatory responses. In our ongoing studies, we find that while the number of $B c l-2$ expressing cells is similar in the IL- $1 \beta$-treated and the TNF $\alpha$-treated rat brains, the number of Bax expressing cells in the IL- $1 \beta$-treated rat brain is significantly more than that in the TNF $\alpha$-treated rat brain (data not shown). It is possible that the difference between IL-1 $\beta$ and $\mathrm{TNF} \alpha$ in induction of apoptotic cell death is associated with differential expression of $\mathrm{Bax}$ and $\mathrm{Bcl}-2$ stimulated by them. In addition, the density of the activated microglia stimulated by $\mathrm{TNF} \alpha$ was significantly less than that stimulated by IL- $1 \beta$ in the present study. More activated microglia in IL- $1 \beta$-treated brain may contribute to more apoptosis in these rat brains compared with in the TNF $\alpha$-treated rat brain, although the detailed mechanisms remain to be elucidated. We found in our previous study that application of $\mathrm{TNF} \alpha$ antibody was unable to protect LPS-induced OL injury, while an IL-1 receptor antagonist blocked LPS-induced brain injury, suggesting that increased TNF $\alpha$ may not have a direct causal-effect in LPSinduced brain injury (32). The lack of effect of TNF $\alpha$ on developing OLs observed in the current study is consistent with our previous results. Data from both studies indicate that TNF $\alpha$ might not cause severe brain injury in an in vivo setting of experimental conditions like the present study. However, it is premature to exclude TNF $\alpha$ from the list of factors mediating infection and/or inflammation-induced neonatal white matter injury. Our studies primarily look at acute effects. Recent studies have shown that TNF $\alpha$ interferes with the neuroprotective IGF-1 (IGF-1) signaling pathway $(44,45)$. IGF plays important roles in regulation of OL survival and development (46). TNF $\alpha$ may cause injuries to OLs and white matter through its interference with the IGF system and this possibility is worth further investigation.

In summary, intracerebral injection of IL- $1 \beta$, but not TNF $\alpha$, can cause apoptotic cell death and impairment of developing OLs. The AMPA receptor antagonist, NBQX can partially attenuate IL-1 $\beta$ induced apoptotic cell death, but is unable to prevent its deteriorative effect on developing OLs. IL- $1 \beta$ may contribute significantly to white matter injury in the neonatal brain.

\section{REFERENCES}

1. Dammann O, Leviton A 1997 Maternal intrauterine infection, cytokines, and brain damage in the preterm newborn. Pediatr Res 42:1-8

2. Dammann O, Leviton A 1998 Infection remote from the brain, neonatal white matter damage, and cerebral palsy in the preterm infant. Semin Pediatr Neurol 5:190-201

3. Volpe JJ 1997 Brain injury in the premature infant. Neuropathology, clinical aspects, pathogenesis, and prevention. Clin Perinatal 24:567-587

4. Volpe JJ 2001 Neurology of the Newborn. 4th Edition. WB Saunders Co, Philadelphia, pp 231-276

5. Leviton A 1993 Preterm birth and cerebral palsy: is tumor necrosis factor the missing link? Dev Med Child Neurol 35:553-558

6. Deguchi K, Mizuguchi M, Takashima S 1996 Immunohistochemical expression of tumor necrosis factor alpha in neonatal leukomalacia. Pediatr Neurol 14:13-16

7. Deguchi K, Oguchi K, Takashima S 1997 Characteristic neuropathology of leukomalacia in extremely low birth weight infants. Pediatr Neurol 16:296-300

8. Kadhim H, Tabarki B, Verellen G, De Prez C, Rona AM, Sebire G 2001 Inflammatory cytokines in the pathogenesis of periventricular leukomalacia. Neurology $56: 1278-1284$

9. Yoon BH, Romero R, Kim CJ, Koo JN, Choe G, Syn HC, Chi JG 1997 High expression of tumor necrosis factor- $\alpha$ and interleukin-6 in periventricular leukomalacia. Am J Obstet Gynecol 177:406-411

10. Yoon BH, Romero R, Yang SH, Jun JK, Kim IO, Choi JH, Syn HC 1996 Interleukin-6 concentrations in umbilical cord plasma are elevated in neonates with white matter lesions associated with periventricular leukomalacia. Am J Obstet Gynecol $174: 1433-1440$ 
11. Yoon BH, Jun JK, Romero R, Park KH, Gomez R, Choi JH, Kim IO 1997 Amniotic fluid inflammatory cytokines (interleukin-6, interleukin- $1 \beta$, and tumor necrosis factor- $\alpha$ ), neonatal brain white matter lesions, and cerebral palsy. Am J Obstet Gynecol 177:19-26

12. Duncan JR, Cock ML, Scheerlinck JP, Westcott KT, McLean C, Harding R, Rees SM 2002 White matter injury after repeated endotoxin exposure in the preterm ovine fetus. Pediatr Res 52:941-949

13. Mallard C, Welin AK, Peebles D, Hagberg H, Kjellmer I 2003 White matter injury following systemic endotoxemia or asphyxia in the fetal sheep. Neurochem Res 28:215-223

14. Bell MJ, Hallenbeck JM 2002 Effects of intrauterine inflammation on developing rat brain. J Neurosci Res 70:570-579

15. Cai Z, Pan ZL, Pang Y, Evans OB, Rhodes PG 2000 Cytokine induction in fetal rat brain and brain injury in neonatal rats after maternal lipopolysaccharide administration. Pediatr Res 47:64-72

16. Barone FC, Arvin B, White RF, Miller A, Webb CL, Willette RN, Lysko PG, Feuerstein GZ 1997 Tumor necrosis factor-alpha. A mediator of focal ischemic brain injury. Stroke 28:1233-1244

17. Hagberg H, Gilland E, Bona E, Hanson LA, Hahin-Zoric M, Blennow M, Holst M, McRae A, Soder O 1996 Enhanced expression of interleukin (IL)-1 and IL-6 messenger RNA and bioactive protein after hypoxia-ischemia in neonatal rats. Pediatr Res 40:603-609

18. Hara H, Friedlander RM, Gagliardini V, Ayata C, Fink K, Huang Z, ShimizuSasamata M, Yuan J, Moskowitz MA 1997 Inhibition of interleukin 1beta converting enzyme family proteases reduces ischemic and excitotoxic neuronal damage. Proc Natl Acad Sci U.S.A. 94:2007-2012

19. Loddick SA, Rothwell NJ 1996 Neuroprotective effects of human recombinant interleukin-1 receptor antagonist in focal cerebral ischaemia in the rat. J Cereb Blood Flow Metab 16:932-940

20. Nawashiro H, Martin D, Hallenbeck JM 1997 Neuroprotective effects of TNF binding protein in focal cerebral ischemia. Brain Res 778:265-271

21. Relton JK, Martin D, Thompson RC, Russell DA 1996 Peripheral administration of Interleukin-1 receptor antagonist inhibits brain damage after focal cerebral ischemia in the rat. Exp Neurol 138:206-217

22. Holmin S, Mathiesen T 2000 Intracerebral administration of interleukin- $1 \beta$ and induction of inflammation, apoptosis, and vasogenic edema. J Neurosurg 92:108-120

23. Takahashi JL, Giuliani F, Power C, Imai Y, Yong VW 2003 Interleukin-1 $\beta$ promotes oligodendrocyte death through glutamate excitotoxicity. Ann Neurol 53:588-595

24. Megyeri P, Abraham CS, Temesvari P, Kovacs J, Vas T, Speer CP 1992 Recombinan human tumor necrosis factor-alpha constricts pial arterioles and increases blood-brain barrier permeability in newborn piglets. Neurosci Lett 148:137-140

25. Selmaj KW, Raine CS 1988 Tumor necrosis factor mediates myelin and oligodendrocytes damage in vitro. Ann Neurol 23:339-346

26. Selmaj K, Raine CS, Farooq M, Norton WT, Brosnan CF 1991 Cytokine cytotoxicity against oligodendrocytes. Apoptosis induced by lymphotoxin. J Immunol 147:15221529

27. Allen SM 2002 Varied actions of proinflammatory cytokines on excitotoxic cell death in the rat central nervous system. J Neurosci Res 67:428-434
28. Liu XH, Xu H, Barks JD 1999 Tumor necrosis factor- $\alpha$ attenuates N-methyl-Daspartate-mediated neurotoxicity in neonatal rat hippocampus. Brain Res 851:94-104

29. Arnett HA, Mason J, Marino M, Suzuki K, Matsushima GK, Ting JP 2001 TNF-alpha promotes proliferation of oligodendrocyte progenitors and remyelination. Nat Neurosci 4:1116-1122

30. Barger SW, Horster D, Furukawa K, Goodman Y, Krieglstein J, Mattson MP 1995 Tumor necrosis factor alpha and beta protect neurons against amyloid beta-peptide toxicity: Evidence for involvement of kappa-B-binding factor and attenuation of peroxide and $\mathrm{Ca}^{2+}$ accumulation. Proc Natl Acad Sci U.S.A. 92:9328-9332

31. Pang Y, Cai Z, Rhodes PG 2003 Disturbance of oligodendrocyte development, hypomyelination and white matter injury in the neonatal rat brain after intracerebral injection of lipopolysaccharide. Brain Res Dev Brain Res 140:205-214

32. Cai Z, Pang Y, Lin S, Rhodes PG 2003 Differential roles of tumor necrosis factor-alpha and interleukin-1beta in lipopolysaccharide-induced brain injury in the neonatal rat. Brain Res 975:37-47

33. Back SA, Han BH, Luo NL, Chricton CA, Xanthoudakis S, Tam J, Arvin KL, Holtzman DM 2002 Selective vulnerability of late oligodendrocyte progenitors to hypoxia-ischemia. J Neurosci 22:455-463

34. Follett PL, Rosenberg PA, Volpe JJ, Jensen FE 2000 NBQX attenuates excitotoxic injury in developing white matter. J Neurosci 20:9235-9241

35. Patel HC, Boutin H, Allan SM 2003 Interleukin-1 in the brain: mechanisms of action in acute neurodegeneration. Ann NY Acad Sci 992:39-47

36. Back SA, Luo NL, Borenstein NS, Levine JM, Volpe JJ, Kinney HC 2001 Late oligodendrocyte progenitors coincide with the developmental window of vulnerability for human perinatal white matter injury. J Neurosci 21:1302-1312

37. Dammann O, Durum S, Levition A 2001 Do white cells matter in white matter damage? Trends Neurosci 24:320-324

38. Stoll G, Jander S 1999 The role of microglia and macrophages in the pathophysiology of the CNS. Prog Neurobiol 58:233-247

39. Hu S, Sheng WS, Ehrlich LC, Peterson PK, Chao CC 2000 Cytokine effects on glutamate uptake by human astrocytes. Neuroimmunomodulation 7:153-159

40. Ye ZC, Sontheimer H 1996 Cytokine modulation of glial glutamate uptake: a possible involvement of nitric oxide. Neuroreport 7:2181-2185

41. Merrill JE 1991 Effects of interleukin-1 and tumor necrosis factor-alpha on astrocytes, microglia, oligodendrocytes, and glial precursors in vitro. Dev Neurosci 13:130-137

42. Liu Y, Silverstein FS, Skoff R, Barks JD 2002 Hypoxic-ischemic oligodendroglial injury in neonatal rat brain. Pediatr Res 51:25-33

43. Cheng YJ, Yang BC, Hsieh WC, Huang BM, Liu MY 2002 Enhancement of TNF-alpha expression does not trigger apoptosis upon exposure of glial cells to lead and lipopolysaccharide. Toxicology 178:183-191

44. Venters HD, Dantzer R, Kelley KW 2000 A new concept in neurodegeneration: TNF-alpha is a silencer of survival signals. Trends Neurosci 23:173-180

45. Venters HD, Tang Q, Liu Q, VanHoy RW, Dantzer R, Kelley KW 1999 A new mechanism of neurodegeneration: a proinflammatory cytokine inhibits receptor signaling by a survival peptide. Proc Natl Acad Sci U.S.A. 96:9879-9884

46. Orentas DM, Miller RH 1998 Regulation of oligodendrocyte development. Mol Neurobiol 18:247-259 